\title{
The Effect of Biofilm Growth on Wall Shear Stress in Drinking Water PVC Pipes
}

\author{
Muthukrishna vellaisamy Kumarasamy*, Phylicia Megan Maharaj \\ Civil Engineering Programme, School of Engineering, University of KwaZulu-Natal, \\ Durban 4041, South Africa
}

Received: May 2, 2015

Accepted: June 20, 2015

\begin{abstract}
Water quality in the distribution system depends on the operation and design of the system - including the treatment process. In addition to water quality, high energy costs and increasing demand require that the water supply infrastructure should function optimally. The change in roughness of pipe surface is common in a distribution system, which is influenced by factors such as tuberculation, sedimentation, and biofilm growth. Among these, biofilm growth is the focus of our study. One of the factors affecting biofilm growth is the velocity field of the fluid in contact with the microbial layer, or vice versa. Literature states that a high shear force will result in denser, stronger biofilms, while low shear forces result in a monolayer of biofilm cells. Most investigations focused on relating biofilm growth and variation of different factors such as disinfectants, pipe materials, water quality, etc. One aspect that affects the shear stress is the roughness of a solid surface over which the fluid flows. Investigation into the relationship between shear stress and biofilm growth was carried out with poly vinyl chloride pipe coupons attached to the bottom of the channel, where the biofilms were allowed to grow. Velocity components at different locations along the channel were measured by laser Doppler anemometer for further analysis. The results indicated that the shear stress only increased slightly with younger biofilm layers, and that further analysis is required with thicker and more mature biofilms.
\end{abstract}

Keywords: turbulent flow, biofilm growth, Reynold's stress

\section{Introduction}

Potable water may be described as water that may be consumed in any desired fashion and amount causing no health concerns. Water quality in the water distribution system (WDS) depends on a number of factors, one of which is biofilm growth. The contamination in WDS is due to fixed bacteria multiplication, their detachment, and transport [1]. Although complete microbial elimination from the distribution system is almost impossible, water suppliers try to control bacterial growth using disinfectants. A large fraction of biomass is found attached at the pipe walls in WDS in most flow conditions [2]. The suspended bacterial densi-

*e-mail: kumarasamy@ukzn.ac.za ty increases in WDS from the time it exits the treatment facility to the time it reaches consumer taps because of decaying disinfectant, hydraulic residence time, and corrosion [3]. Previous studies [4, 5] show that biofilm growth on the pipe wall affects the friction factor and lifespan of the pipe networks.

Even though biofilm may appear to be a slimy layer, it consists of dynamic communities of microbial cells and colonies within extra cellular polymeric substance (EPS). Biofilm growth can be limited by stable and higher flow rates as they produce thinner and more cohesive layers less prone to detachment of bacterial cells into the distribution system. It is difficult to maintain these flow conditions within drinking water networks and it may not be feasible [3]. In a water column, bacterial cells behave like particles, 
where the rate of mixing and settling of cells on the substratum depends on the flow regime. The nature of biofilms that develop in flowing water systems depends mainly on hydrodynamic conditions [6]. The hydraulic conditions in WDS vary daily and seasonally from stagnation to high flow as demands vary. Stagnation of water occurs in places where the water consumption is low, and in storage reservoirs [3]. In stagnant conditions the transport of the bacteria from the bulk phase to the substratum occurs due to Brownian diffusion, sedimentation, and cell motility [7]. Besides these factors, disinfectant efficiency is also impacted by flow conditions [3]. When the velocity of the water increases it causes a great flux of nutrients, with disinfectants inside the distribution system and an increase in fluid shear on the pipe surfaces $[8,9]$. In dynamic conditions transport is due to convection and diffusion. If the flow becomes turbulent, microorganisms are transported by eddies in the flow. Studies have also shown that the type of disinfectant $[1,10$ 13], pipe material [10, 14-16], hydrodynamics [6, 9, 12, 14, 17], availability of nutrients [1, 11, 18-24], and microbial manifestation in the WDS can lead to evident changes in microbial activities. Biofilm development is a result of pioneer attachment, subsequent attachment, and growth of EPS - an essential substance in keeping biofilm organisms together that provides protection against stress, predation, and exposure to a hostile environment. Bacterial growth and EPS development have an adverse effect in WDS, which can cause substantial energy loss resulting from increased frictional resistance and increased heat transfer resistance.

Shear stress affects biofilm thickness, density, structure, and surface roughness during biofilm formation. The literature shows that detachment occurs when shear stress is greater than the internal strength of the biofilm structure $[9,25,26]$. Many researchers [9, 27-29] have researched the influence of shear stress on biofilm growth and detachment characteristics. Information on the impact of shear stress on microbial biofilms may be helpful in providing an understanding of the functionality and mechanism relationship of biofilm during creation, growth, and subsequent effects on biofilm properties. This may also contribute to a fundamental understanding of the physical and physiological behavior of biofilms to adapt to changes in environmental systems [26]. As the biofilm continues to develop, the biofilm can spread to uninfected areas when environmental conditions are favorable. Occasionally, cells will detach from the biofilm and repeat the cycle infection on new surfaces. Erosion due to high shear contributes to a smooth biofilm surface, and sloughing leads to an increase in biofilm surface roughness.

Biofilms respond to high shear stresses by relying on defensive mechanisms to resist detachment [14]. Van Vuuren and Dijk [15] found that each substrate has its own detaching velocity at which adhesion is overcome, and these velocities are in the range 3-4 m/s. However, for ordinary water networks such velocities are unlikely [15]. Schultz [30] studied turbulent boundary layers on surfaces covered by filamentous algal biomass. He used a two-component laser Doppler anemometer (LDA) and compared mean velocity profiles, axial and wall-normal turbulence, and shear stresses for the flows over smooth and rough surfaces. His study identified a significant increase in skin friction co-efficient for algae-covered surfaces.

Studies have shown that shear stress plays a role on the structure of biofilm during development. Pei-Shi et al. [31] pointed out that shear stress will affect biofilm thickness, density, and surface roughness during biofilm accumulation [26]. Paul et al. [9] showed the increase in compactness due to how external forces significantly influence biofilm resistance to detachment. Therefore, biofilms may not be sloughed off at these high velocities but become more compact and stable. In a study carried out by [31], it was further indicated - in addition to higher shear stress - that other aspects such as the microbes forming the biofilm, the strength and cohesiveness of the biofilms, and the type of fluids in which the biofilm grows should be taken into consideration for biofilm detachment. Researchers $[9,25]$ concluded that sloughing may occur with high liquid shear in a range of 0.1-13 $\mathrm{Pa}$, combined with low bacterial growth rates. Pipe roughness does to some extent influence bacterial colonization due to an increased adhesion with roughness of the pipe surface. The information gathered from laboratory experiments is often misleading of the real distribution networks and they mostly concentrate on specific parameter that influence the biofilms rather than activities between parameters. Therefore, future experiments should be conducted to find relationships between these parameters and biofilm growth. Field studies in real distribution networks avoid the limitations associated with laboratory experiments, which mimic distribution systems.

Removal of biofilm usually involves cutting of pipes sections from the network or inserting devices into the water flow, which can be expensive and difficult. This research is focused on laboratory-controlled continuous flow experiments to investigate the increase in shear stress due to the growth of biofilm on pipe coupons under specified conditions. The increase in shear stress is expected due to the change in the pipe surface roughness profile induced by biofilm attachment and growth. Biofilm may not be detached in a low shear stress range (less than $0.1 \mathrm{~Pa}$ $[9,25])$. However, quantifying biofilm detachment was not a part of our current research.

\section{Methodology}

Pipe coupons were cut from water supply PVC pipes and immersed into a beaker with treated drinking water for a month for the biofilms to grow on the coupons after initial sterilization of the entire setup. During this period, the beaker was covered with aluminum foil to prevent algae growth. These coupons were then arranged into a grove on the channel bottom at a location downstream of the leading edge, where fully developed turbulent flow conditions occur. To access the effects of different hydrodynamic conditions on biofilm growth, different flow conditions were adopted. The first condition was stagnation (no shear), the second was constant shear, and the third was constant shear with turbulence. 


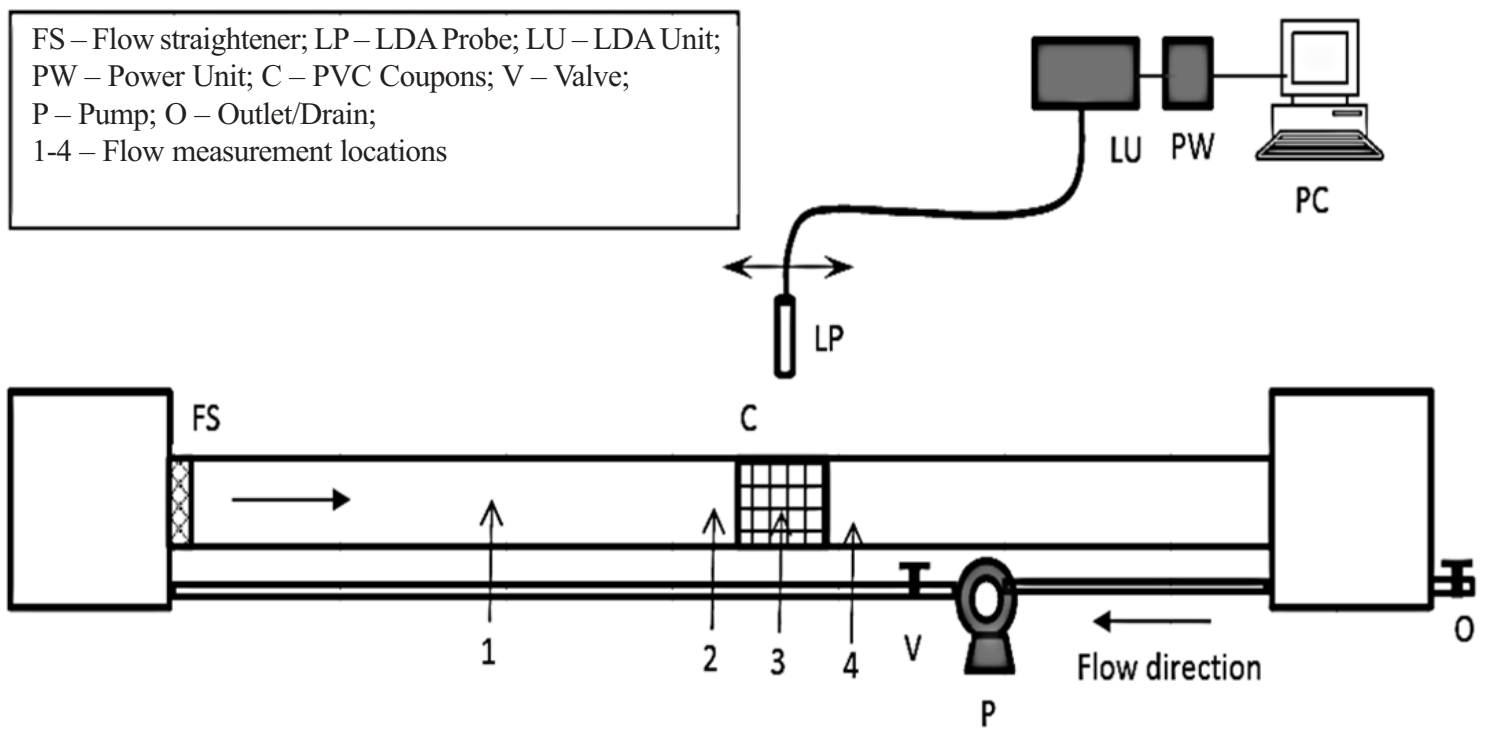

Fig. 1. Illustration of experimental setup (plan view) shows the points at which PVC coupons ("C") were arranged for biofilm samples and LDA setup.

LDA was used to measure the flow. Four different locations were selected to take flow measurements. Fig. 1 illustrates the experimental setup and shows location of PVC coupons, different points of velocity measurements along the test channel, and the LDA system. Point 1 is the hydrodynamic entrance region where the flow is not fully developed. Point 2 is about $1 \mathrm{~m}(\approx 10$ times of hydraulic diameter, $D_{h}$ ) from the entrance where the flow is fully developed. Point 3 is over the coupons, and point 4 is after the biofilm coupons. For turbulent flow, the instantaneous velocity $U(\mathrm{x}, \mathrm{t})$ is given by the average flow velocity $(\bar{U})$ and the fluctuating velocity $\left(U^{\prime}\right)$, which is:

$$
U_{i}=\bar{U}+U
$$

Velocity components in $\mathrm{x}$ and $\mathrm{z}$ directions were measured by LDA at different depths, similar to Eq. (1). According to Reynolds' theory, the turbulent shear stress among two layers of a fluid a small distance apart for linear flow is given as:

$$
\tau=\rho u^{\prime} w^{\prime}
$$

...where $u$ ' and $w^{\prime}$ are fluctuating components of velocity in the in the $\mathrm{x}$ and $\mathrm{z}$ direction of flow. The friction co-efficient is related with a ratio between shear velocity and average velocity measured. Characteristics of surface roughness profile can be defined as a rough or smooth boundary based on viscous sub-layer thickness, as follows:

$$
\delta^{\prime}=\frac{5 \gamma}{U_{*}}
$$

...where $\delta^{\prime}-$ viscous sub-layer, $\gamma-$ kinematic viscosity, and $U_{*}$ - shear velocity.

The limitations encountered were due to the fact that PVC pieces were not all identical in shapes and sizes.
This could have impacted the flow over the samples. However, at most care has been taken while arranging samples. The biofilm cultivated for the experiment needed to be cultivated quickly; these ideal conditions do not apply to distribution systems. Biofilm in distribution systems usually takes months to develop.

\section{Results and Discussion}

The velocity profiles at different points along the channel are shown in Fig. 2, which shows a logarithmic velocity profile along the depth of flow. This was expected as stated in the literature; the velocity profile for open channel flow follows this trend. The results follow the same trend that was obtained from the experiments by [30]. A slight increase in the Reynolds stress from point one to point three, where the biofilm samples were situated, can be noted in Fig. 3. This may be due to biofilm growth on the PVC coupons. This also could be due to irregularities in the arrangement of coupons [32].

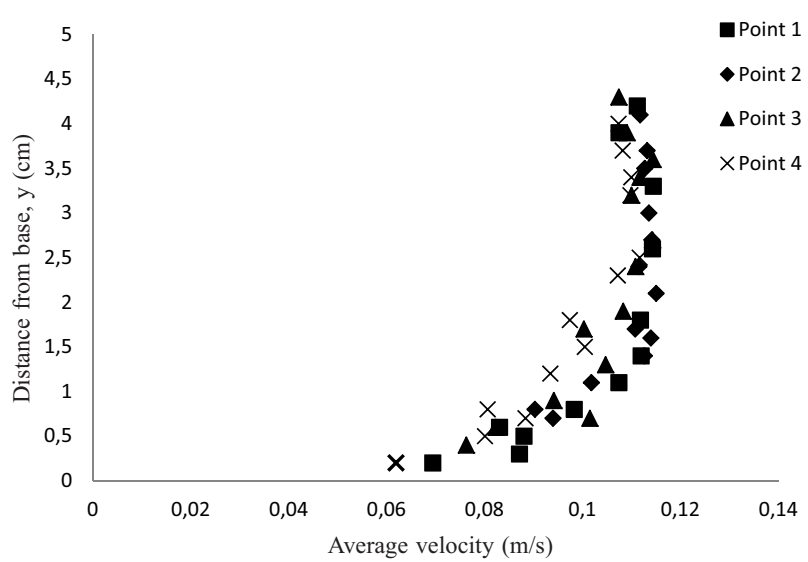

Fig. 2. Graph showing the velocity profile. 
Table 1. Reynolds stress and friction co-efficient.

\begin{tabular}{|c|c|c|c|c|c|c|}
\hline \multirow{2}{*}{ Pipe Surface } & \multicolumn{2}{|c|}{ Shear stress } & \multirow{2}{*}{$\begin{array}{c}\text { Ave Velocity } \\
\bar{U}(\mathrm{~m} / \mathrm{s})\end{array}$} & \multirow{2}{*}{$\begin{array}{c}\text { Shear velocity } \\
U_{*}(\mathrm{~m} / \mathrm{s})\end{array}$} & \multirow{2}{*}{$\begin{array}{c}\text { Friction } \\
\text { co-efficient } \mathrm{C}_{\mathrm{f}}\end{array}$} & \multirow{2}{*}{$\begin{array}{l}\text { Viscous sub- } \\
\text { layer } \delta^{\prime}(\mathrm{mm})\end{array}$} \\
\hline & $u^{\prime} w^{\prime}(\mathrm{m} / \mathrm{s})^{2}$ & $\rho u^{\prime} w^{\prime}(\mathrm{Pa})$ & & & & \\
\hline Smooth & 0.000042 & 0.0419 & 0.1004 & $6.48 \times 10^{-3}$ & 0.00835 & \multirow{2}{*}{0.77} \\
\hline PVC with Biofilm & 0.000054 & 0.0541 & 0.0939 & $7.36 \times 10^{-3}$ & 0.0122 & \\
\hline
\end{tabular}

The turbulent shear stress profile for point 4 (downstream of point 3 ) in comparison with other points has been plotted in Fig. 3, which is a stream-wise variation. This response agrees with the results presented in [30] and [33]. It can be noted from Fig. 3 that the turbulent shear stress is constant near the solid surface. Hence choosing values, as pointed out in the Fig. 3, where the friction coefficient can be determined as given in Table 1.

The friction factor calculated from the experimental results was slightly higher compared to a smooth pipe with the same flow condition as expected. The results are gathered from a similar previous experiment by Schultz [30], who investigated the increased shear stress due to algal growth over a ship's surface. The dimensionless plots in [30] show a distinct increase in turbulent normal stresses due to algal growth. Similar trends with the current biofilm experiment were anticipated. It has been concluded by [6] that the range of shear stresses between 0.12 and $0.23 \mathrm{~Pa}$ impact young drinking water biofilms (four to 12 weeks) to detach. This is understood in this study that for younger biofilms (four weeks), low shear stress (0.054 Pa) wouldn't be sufficient to detach. Similar results on detachment of biofilm under shear stress range of 0.1 to $13 \mathrm{~Pa}$ has been observed by previous researchers $[9,25]$.

\section{Conclusions}

The results showed that a change was induced due to the presence of the biofilm samples. The change was not only brought about by the biofilm but may also be caused by the pieces of PVC that induce an internal boundary layer due to their height differences and depressions between samples. Cultivation conditions do not mimic real environments of a water supply pipeline because the time frame taken in the experiment was only a month, whereas pipelines accumulate biofilms for many months.

The experiment showed that the biofilm present on the coupons was only a preliminary layer and the thickness of which is less than laminar sub-layer. In order to have some significant change in shear to occur, we should have thick matured biofilm of at least $800 \mu \mathrm{m}$. Microbial growth in WDS is complex, and many factors contribute to the growth. In order to improve the experiment for future research, the following points are considered:

- The experiment should be carried out over a longer period and more data points should be taken to enable more realistic results.

- A monolithic structure should be used instead of PVC coupons. Casting a cement mortar line of steel pipeline is common in the uMgeni distribution system in South Africa.

- The experiment should be conducted in a closed conduit with pressure drop, which is also important.

- Monitoring the chlorine in the water is essential as the samples were cultivated in untreated water and placed in a system with treated water.

- Availability of nutrients such as ammonia, nitrates, and phosphates may induce biofilm growth; hence it is vital to monitor essential nutrients during the experiment.

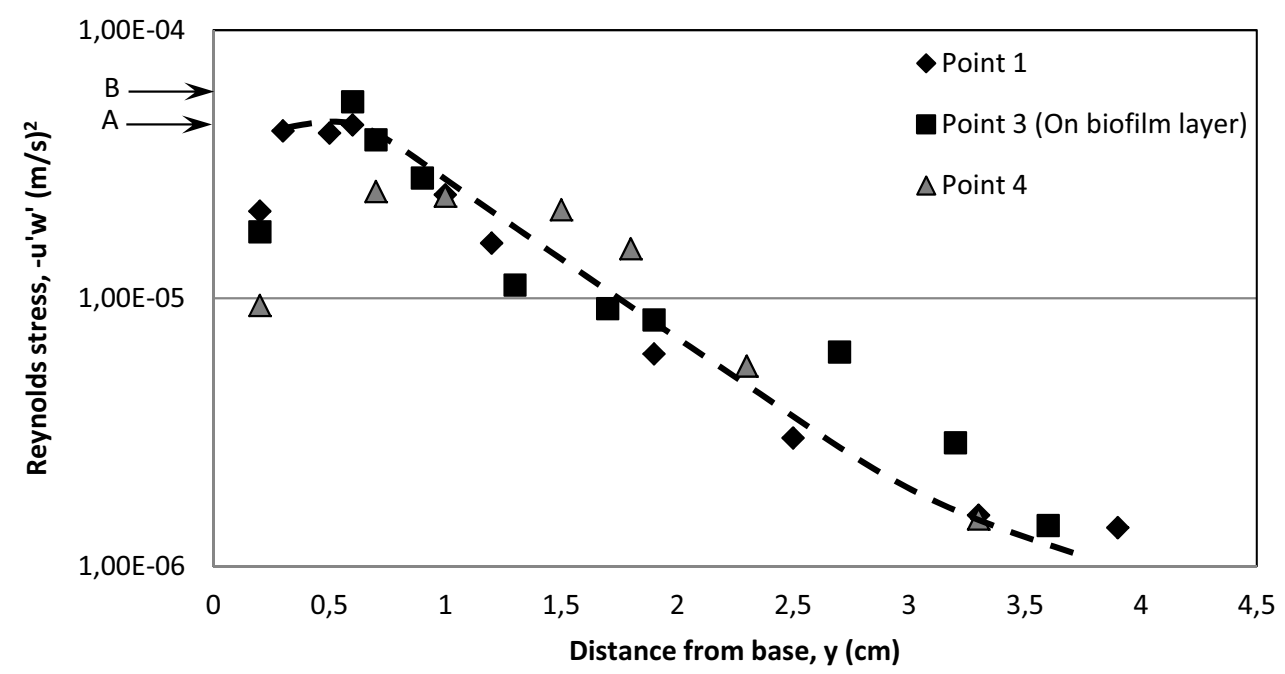

Fig. 3. Turbulent (Reynolds) shear stress profiles on sample coupons and along the channel (line denotes the shear stress profile for PVC without biofilm): A - Reynolds stress at wall for smooth PVC without biofilm and B - Reynolds stress at wall for PVC with biofilm. 


\section{Acknowledgements}

Authors acknowledge the support provided by Water Research Commission South Africa for this study through the Project K5/2372.

\section{References}

1. GOUIDER M., BOUZID J., SAYADI S., MONTIEL A. Impact of orthophosphate addition on biofilm development in drinking water distribution systems. J. Hazard. Mater., 167, 1198, 2009

2. SRINIVASAN S., HARRINGTON G.W., XAGORARAKI I., GOEL R. Factors affecting bulk to total bacteria ratio in drinking water distribution systems. Water Res., 42, (13), 3393, 2008.

3. MANUEL C.M., NUNES O.C., MELO L.F. Dynamics of Drinking Water Biofilm in Flow/non-Flow Conditions. Water Res., 41, 551, 2007.

4. VAN VUUREN S.J., DIJK M.V. Determination of the change in Hydraulic Capacity in Pipelines. Water Research Commission South Africa. Research report No. 1820/1/12, 2012.

5. SIMOES L.C., SIMOES M. Biofilms in drinking water: problems and solutions. RCS Advances, pp. 2520-2533, 2013.

6. ABE Y., SKALI-LAMI S., BLOCK J.C., FRANCIUS G. Cohesiveness and hydrodynamic properties of young drinking water biofilms. Water Res., 46, 1155, 2012.

7. BUSSCHER H.J., VAN DER MEI H.C. Microbial Adhesion in Flow Displacement Systems. Clin. Microbiol. Rev. 19, (1), 127, 2006

8. HORI K., MATSUMOTO S. Bacterial Adhesion: From Mechanism to Control. Biochem. Eng. J. 48, 424, 2010

9. PAUL E., OCHOA J.C., PECHAUD Y., LIU Y., LINÉ A. Effect of shear stress and growth conditions on detachment and physical properties of biofilms. Water Res., 46, 5499, 2012.

10. AL-JASSER A.O. Chlorine decay in drinking-water transmission and distribution systems: Pipe service age effect. Water Res., 41, 387, 2007.

11. PRESSMAN J.C., LEE W.H., BISHOP P.L., WAHMAN D.G. Effect of free ammonia concentration on monochloramine penetration within a nitrifying biofilm and its effect on activity, viability, and recovery. Water Res., 46, 882, 2012.

12. KUMARASAMY M. The effect of age on the friction of large diameter potable water cement mortar lined pipelines - Data Report. Water Research Commission South Africa. Project No: K5/2372. 2015.

13. SE-KEUN PARK, YEONG-KWAN KIM. Effect of chloramine concentration on biofilm maintenance on pipe surfaces exposed to nutrient-limited drinking water. Water SA. 34, (3), 373, 2008.

14. LEHTOLA M.J., LAXANDER M., MIETTINEN I.T., HIRVONEN A., VARTIAINEN T., MARTIKAINEN P.J. The effects of changing water flow velocity on the formation of biofilms and water quality in pilot distribution system consisting of copper or polyethylene pipes. Water Res., 40, 2151, 2006.

15. VAN VUUREN S., DIJK M.V. Review of factors that influence the energy loss in pipelines and procedures to evaluate the hydraulic performance for different internal conditions. Water Research Commission South Africa, Research Report No. 1269/1/06, 2006.
16. KOPPEL T., VASSILJEV A. Calibration of a model of an operational water distribution system containing pipes of different age. Adv. Eng. Softw. 40, 659, 2009.

17. CHRISTENSEN R.T. Age Effects on Iron-Based Pipes in Water Distribution Systems. PhD Thesis, Civil and Environmental Engineering, Utah State University. 2009.

18. BERRY D., XI C., RASKIN L. Effect of growth conditions on inactivation of Escherichia coli with monochloramine. Environ. Sci. Technol. 43, (3), 884, 2009.

19. SAKYI P.A., ASARE R., ANANI C., DAMPARE S.B. Nutrient-Induced Growth of Coliform and HPC Bacteria in Drinking-Water Pipes. Journal of Environmental Protection. 3, 508, 2012

20. LEE W.H., PRESSMAN J.G., WAHMAN D.G., BISHOP P.L. Characterization and application of a chlorine microelectrode for measuring monochloramine within a biofilm. Sensor. Actuat. B-Chem., 145, 734, 2010.

21. LEE W.H., WAHMAN D.G., BISHOP P.L., PRESSMAN J.G. Free chlorine and monochloramine application to nitrifying biofilm: comparison of biofilm penetration, activity, and viability. Environ. Sci. Technol. 45, 1412, 2011.

22. WAHMAN D.G., WULFECK-KLEIER K.A., PRESSMAN J.G. Monochloramine disinfection kinetics of Nitrosomonas europaea by propidium Monoazide Quantitative PCR and Live/Dead BacLight methods. Appl. Environ. Microb. 75, (17), 5555, 2009.

23. ZHANG Y., EDWARDS M. Nutrients and metals effects on nitrification in drinking water systems. J. Am. Water Works Ass., 102, (7), 56, 2010.

24. ZHOU L., ZHANG Y., LI G. Effect of pipe material and low level disinfectants on biofilm development in a simulated drinking water distribution system. J. Zhejiang Univ. Sci. A. 10, (5), 725, 2009.

25. DERLON N., MASSE A., ESCUDIE R., BERNET N., PAUL E. Stratification in the cohesion of biofilms grown under various environmental conditions. Water Res., 42, (89), 2102, 2008

26. MOLOBELA I.P., HO W. Impact of shear on the formation and structure of microbial biofilms, University of South Africa, 2011.

27. ROCHEX A., GODON J.J., BERNET N., ESCUDIE R. Role of shear stress on composition, diversity and dynamics of biofilm bacterial communities. Water Res., 42, (20), 4915, 2008.

28. ROCHEX A., MASSE A., ESCUDIÉ R., GODON J.J., BERNET N. Influence of abrasion on biofilm detachment: evidence for stratification of the biofilm. J. Ind. Microbiol. Biot. 36, 467, 2009.

29. PARIS T., SKALI-LAMI S., BLOCK J.C. Effect of wall shear rate on biofilm deposition and grazing in drinking water flow chambers. Biotechnol. Bioeng. 97, (6), 1550, 2007.

30. SCHULTZ M.P Turbulent boundary layers on surfaces covered with filamentous algae, J. Fluid Eng-T. ASME, 122, 357, 2000.

31. PEI-SHI Q., WEN-BIN W., ZHENG Q. Effect of Shear Stress on Biofilm Morphological Characteristics and the Secreation of Extracellular Polymeric Substances. Harbin: Harbin institute of Technology. 2008.

32. MAHARAJ P.M. The change in shear stress due to biofilm growth in drinking water distribution systems. BSc (Eng.) dissertation. University of KwaZulu-Natal, South Africa. 2014.

33. MARCO FERRO, Experimental study on turbulent pipe flow Linn'e Flow Centre KTH Mechanics SE-100 44 Stockholm, Sweden. 2012. 
